\title{
Heterogeneous Human Capital and Environment Influence Mechanism of FDI: An Empirical Research Based on the Panel Data Derived from Provinces of China
}

\author{
Jie Gao \\ Economics School, Jinan University, Guangzhou, China \\ Email: 1253112495@qq.com \\ Received 22 February 2016; accepted 20 March 2016; published 23 March 2016 \\ Copyright (@ 2016 by author and Scientific Research Publishing Inc. \\ This work is licensed under the Creative Commons Attribution International License (CC BY). \\ http://creativecommons.org/licenses/by/4.0/ \\ (c) (i) Open Access
}

\begin{abstract}
In this paper, the human capital is divided into two kinds of types: heterogeneous human capital and coessential human capital, and the environmental impact mechanism of FDI in different human capital is studied by using the panel data from 1999 to 2012 . The research shows that, in general, the FDI investment will not produce pollution effect on the environment; but in fact, it is the heterogeneous human capital in the human capital, which leads to the emission reduction effect of FDI. In contrast, FDI investment in high homogeneous human capital will lead to environmental degradation.
\end{abstract}

Keywords

FDI, Environmental Pollution, Heterogeneous Human Capital

\section{Introduction}

The rapid growth of foreign direct investment in the past thirty years has made great contributions to the development of China's economy. Foreign investors bring capital, technology and management experience to China, but also lead to a dispute about the environmental impact of FDI. Given the fact that FDI plays an important role in Chinese economy, question arises as to whether FDI has turned China into "pollution haven". The answers have come with a fair bit of ambiguity as the empirical findings. For example, Sha and Shi [1] showed that FDI caused the deterioration of China's environment, and $1 \%$ of the foreign capital enterprise asset growth would 
lead to $0.358 \%$ of the industrial waste gas growth. Fu and $\mathrm{Li}$ [2] showed that the relation between environmental regulation and FDI was negative, which indicated that environmental regulation was a very important factor affecting FDI's location and pollution haven effect existed among China’s provinces. Zhang and Jiang [3] found that the inflow of FDI didn't promote the environmental protection technology while it entered mainly into the heavily polluting industries. Simultaneously, it also led to the loose of the environment regulation. To sum up, the inflow of FDI has a negative impact on the environmental in China. Other findings, however, do not lend support to "pollution haven hypothesis". He [4] was directly to the opposite point of view: because of foreign technology and the higher efficiency of energy use, the technical spillover effect of foreign enterprises improved the host country environmental protection technology, so as to improve the host country's environment quality. $\mathrm{Xu}$ and Deng [5] indicated that FDI was conducive to the improvement of China's environmental pollution, which was mainly due to the FDI tend to use more advanced production technologies and pollution emission system, the optimization and upgrading of industrial structure have helped to reduce resource consumption and pollution emissions. Nie and Liu [6] suggested FDI helped to improve the environment of the city, from the view of city regional distribution in China, compared with the eastern city, FDI was more conducive to the improvement of ecological environment in central and western city. Many scholars have attempted to explore whether FDI turns China into "pollution heaven”, but empirical research has been difficult to get a clear answer. In order to study the problem of China, the paper briefly describes the main research results of Chinese and foreign scholars in this field, and the research ideas of this paper are drawn from these studies.

\section{Literature Review}

Scholars mainly from two angles to confirm the "pollution heaven hypothesis", the first was to study the relationship between the strength of environmental regulation and FDI location choice. List and Co [7] use logit model to study the impact of environmental regulation on the location decision of multinational enterprises; Xing and Kolstad [8] study the extent to which FDI from the United States is influenced by the host country's environmental regulation; Zhang and Fu [9] verify the sensitivity of FDI on regional environmental regulation by using regional analysis so as to provide evidence for China as "pollution heaven”. The second is to study the relationship between FDI and pollutant emission; He [4] used the panel data of 29 provinces and cities in China to establish simultaneous equations to analyze the relationship between pollutant emissions and FDI; Baek and Koo [10] examined the long-term and short-term relationship between FDI and environmental pollution in China and India by using time series cointegration analysis and vector autoregressive model; Cole et al. [11] investigate the relationship between economic growth and industrial pollutants emission for 112 major cities in China between 2001 to 2004.

However, some scholars have questioned the hypothesis. Birdsall and Wheeler [12] believed that the more open economies, the more easy to attract foreign clean industrial investment, the mechanism of impact of FDI on the host environment was complex, and was not direct as “pollution heaven hypothesis” described; Esleland and Harrison [13] took Latin America as an example to point out that foreign companies were more inclined to adopt clean, high energy efficiency technology. Furthermore, some studies have pointed out that multinational companies in Asia will adopt environment friendly technologies to reduce environmental damage [14]-[16]. And this conclusion is particularly significant in China, South East Asia and Taiwan [17].

Some studies researched the mechanism of FDI's environmental effects. Copeland and Taylor [18] concluded that FDI affect the host environment from three ways, including scale effect, structure effect and technology effect; Dean et al. [19], Eskeland and Harrison [13] argued that the foreign capital can weaken the damage to the environment through technology diffusion effect; Caselli and Coleman [20] showed that developing countries hoped that environment friendly enterprise from technical leader bring in advanced technologies, but the absorption and application capabilities of such environmental friendly technologies are limited to the level of human capital of the country or region. Therefore, the level of human capital can affect the ability of the country or region to absorb the advance technologies, including emission reduction technology [21]. Lian et al. [22], Li and Liu [23], Yang and Lu [24] showed that in the region of abundant human capital, FDI tended to produce the effect of emission reduction, and in region of barren human capital, FDI will cause the deterioration of the quality of the environment.

Most research focused on the impact of FDI on the environment in the view of human capital, but ignored the ingredient of human capital. This paper argues that human capital has the characteristics of heterogeneity, and 
different ingredient of human capital lead to different environmental effects of FDI in the end. Heterogeneous human capital may be the essential factor to absorb advance environmental friendly technology. What's more, foreign enterprises will choose the technology and make location decision on the basis of heterogeneous human capital level. If heterogeneous human capital level in area is higher, foreign enterprises tend to adopt efficient technology to reduce energy consumption cost, and even to layout of high-tech industry in the region. Based on the above analysis, this paper try to measure of heterogeneous human capital and coessential human capital, inspect in different environmental effects of FDI under different types of human capital level, find out the key factors of the emission reduction effects of FDI.

\section{Human Capital, Heterogeneous Human Capital and the Mechanism of FDI's Environmental Effect}

\subsection{The Definition of Heterogeneous Human Capital}

Human capital is the condensation of health, knowledge, experience and professional skills and other factors in labor. Idiosyncratic human capital is a kind of human capital with the property of increasing marginal returns to productivity in specific stage; on the contrary, coessential human capital stage is a kind of human capital with the property of diminishing marginal returns in specific stage. Actually, the stock of heterogeneous human capital is not steady and it will turn into coessential human capital as the property of increasing marginal returns disappear [25].

As a special human capital, heterogeneous human capital is difficult to measure. We believe that the higher education is the major way for the formation of idiosyncratic human capital, there are two reasons with it. Firstly, idiosyncratic human capital has the attribute of increasing marginal returns to productivity, which determines that it is a kind of human capital with knowledge in large quantity and high quality. Elementary and secondary education can only provide the necessary knowledge to save life, but only the higher education can make people obtain revolutionary and advanced knowledge and skills. In practical terms, universities are such place with large amount of knowledge. Secondly, institutions of higher education can summarize knowledge so that people can learn it with high efficiency. But in addition to provide stereotyped knowledge, higher education can improve people's thinking and judgment ability to innovate. So, based on these reasons above, in this paper we define the human capital owned by highly educated labors as "heterogeneous human capital", and human capital owned by no highly educated labors as "coessential human capital”.

\subsection{Heterogeneous Human Capital and FDI Entry}

Blomstrom (1994) examined the relationship between FDI and human capital in Mexico, found that the higher the labor quality, the more advanced the technology level of the foreign capital enterprises. It is true that the stock of human capital under open economy is an important concern for foreign enterprises to enter. As a kind of special capital, human capital exists not only differences in "quantity", is the difference between "quality", and this in the "quality" of the differences in human capital is heterogeneous human capital [26]. In addition to the stock level, foreign companies will determine their own use and transfer technology base on the quality of the host country's human capital quality, the so-called quality is the human capital structure and the heterogeneity of human capital level. The higher level of heterogeneous human capital in a country, the foreign capital enterprises will transfer more advanced technology, and accordingly determine the construction of Corporation R\&D institutions to improve the market competitiveness. On the contrary, the higher level of coessential human capital in a country, the higher the cost of personnel training, lead to the lack of technology transfer, and the transfer of labor-intensive industries to the host country.

\subsection{Heterogeneous Human Capital and Technology Absorptive Capacity}

FDI technology spillover is uncertain, the key is whether the host country has absorptive capacity and application ability. The stronger absorptive capacity of technology in one country is, the stronger the ability of absorption and transformation of external knowledge and technology is. In addition, the absorption capacity depends on a country's economic system and other factors, but also depends on a country's technological capability and R\&D capability, idiosyncratic human capital is key factor to these abilities. Because, firstly, the absorption and application of foreign technologies will need to be done by people, only combined with human capital can this 
technologies or knowledge work. Secondly, from the micro perspective, the research works on absorption and application of foreign technologies are highly specialized, and these works can only done by professionals in higher education, so, as mentioned in section 3.1, human capital owned by these professionals is part of heterogeneous human capital stock. To sum up, heterogeneous human capital is the technical power of economic growth in the region, directly determine the host country absorptive capacity of technology level.

As a result, the uncertainty of the environmental effects of FDI comes from the technical level of the host country, or the technical absorption level of the host country. According to different technology absorption capacity, foreign enterprises choose to make technology transfer and industrial transfer and entry decisions. To determine a country's technological absorptive capacity is the level of heterogeneous human capital in the human capital.

\section{Empirical Model and Variable}

\subsection{Empirical Model}

In order to explore the relationship between different human capital levels and FDI's environmental effect, referring to Lian et al. [22], we set the following three models:

$$
\begin{gathered}
P_{i t}=\alpha+\beta_{1} \mathrm{FDI}_{i t}+\beta_{2} H_{i t} \times \mathrm{FDI}_{i t}+\beta_{X} X_{i t}+\eta_{i}+\tau_{t}+\varepsilon_{i t} \\
P_{i t}=\alpha+\beta_{1} \mathrm{FDI}_{i t}+\beta_{2} \mathrm{CH}_{i t} \times \mathrm{FDI}_{i t}+\beta_{X} X_{i t}+\eta_{i}+\tau_{t}+\varepsilon_{i t} \\
P_{i t}=\alpha+\beta_{1} \mathrm{FDI}_{i t}+\beta_{2} D_{i t} \times \mathrm{FDI}_{i t}+\beta_{X} X_{i t}+\eta_{i}+\tau_{t}+\varepsilon_{i t}
\end{gathered}
$$

The index $i$ and $t$ are on behalf of the area and the year, $P_{i t}$ represents the industrial pollutant per capita emissions, the pollutants in this paper are industrial sulfur dioxide and industrial soot. $H_{i t}, C H_{i t}$ and $D H_{i t}$ are the agent variables of total human capital, homogeneous human capital and idiosyncratic human capital. $X_{i t}$ is a set of regional controls, including energy consumption (energy $\left.{ }_{i t}\right)$, capital intensity $\left(\right.$ capital $\left._{i t}\right)$, the degree of industrialization (industry ${ }_{i t}$ ), unemployment rate (unemploy ${ }_{i t}$ ), population density (density ${ }_{i t}$ ). The variable $\eta_{i}$ stands for time-invariant regional specific effect whilst $\tau_{t}$ denotes to location-invariant time specific effect.

\subsection{Main Variable Descriptions}

\subsubsection{Pollution Variables}

Because the level of per capita emission pollution is able to reflect the quality of the local environment and taking into account the differences of different pollutants, this paper selects industrial sulfur dioxide emissions per capita and industrial soot per capita emissions as pollutant variables. These data come from China Statistical Yearbook (1999-2012).

\subsubsection{FDI and Human Capital}

Referring to the existing researches, this paper selects the utilization of per GDP foreign capital in each region to measure the strength of foreign investment.

This paper adopts the average year of schooling to measure the educational attainment of labor as an indicator of human capital stock at the provincial level. We categorize six levels of schooling for labor as follows: no school, primary, junior secondary, senior secondary, college degree and undergraduate and higher. Human capital can be calculated as follow:

$$
H=2 n_{1}+6 n_{2}+9 n_{3}+12 n_{4}+15 n_{5}+16 n_{6}
$$

$n_{i}$ in Equation (4) is the proportion of labor in the level of education in the $i$ level. Heterogeneous human capital as an abstract concept itself is difficult to measure. We will be defined as "heterogeneous human capital" by the human capital that is owned by the employment of Higher Education (College and above). Human capital owned by those who have not a higher education (illiteracy, primary, secondary and high school) is defined as homogeneous human capital. Referring to Luo [27] and Liu [28] practices, we use the ratio of average year of schooling accumulated by labor in higher education to total average year of schooling as a reference index for heterogeneous human capital, the equation is as follow: 


$$
D H=\frac{15 n_{5}+16 n_{6}}{2 n_{1}+6 n_{2}+9 n_{3}+12 n_{4}+15 n_{5}+16 n_{6}}
$$

Similar to the calculation method of heterogeneous human capital index, we use the ratio of average year of schooling accumulated by labor without a higher education to total average year of schooling as an agent for coessential human capital, the equation is as follow:

$$
C H=\frac{2 n_{1}+6 n_{2}+9 n_{3}+12 n_{4}}{2 n_{1}+6 n_{2}+9 n_{3}+12 n_{4}+15 n_{5}+16 n_{6}}
$$

The data used to construct the variables $H, D H$ and $C H$ are derived from the statistical yearbook of China's labor force (1999-2012).

\subsubsection{Regional Controls}

1) Energy consumption

Since the reform and opening up, China's economic take-off, but before entering the new path to industrialization, China's industrial production is highly dependent on fossil energy consumption. Energy consumption is an important influence factor on the discharge of pollutants from industrial production, especially in the gaseous pollutants. In this paper, the ratio of energy consumption to area GDP is chosen as the index of energy consumption (Table 1 ).

2) Physical capital intensity

In this paper, the index of material capital density is divided by the amount of labor input in the area capital stock. It is generally believed that the level of industrial pollution is affected by the capital density. Traditional industry will use more large-scale equipment in production, so higher capital density means that more high density of pollution exists in the industrial sector of the economy. But to the other point of view, the increase in the density of material capital is the embodiment of technological progress, which means higher technical efficiency, so as to speed up the technical progress of the industry and improve the capacity of emission reduction technology. Therefore it is difficult to determine the influence of material capital density on environmental pollution. The calculation to physical capital stock refers to the perpetual inventory method. We take 1986 as the base period to eliminate price factor, the economic depreciation rate is $9.6 \%$. We use the amount of labor input by the end of the year to measure the number of employment.

3) Unemployment rate

The unemployment rate is likely to affect regional environmental regulation through two ways. Firstly, high unemployment will lead to the local government to mobilize a large number of resources to solve the problem of unemployment, which leads to the reduction of investment in environmental governance. Second, it is because of the high unemployment rate, the regional government and the people are more likely to accept the introduction of

\begin{tabular}{cccccc}
\multicolumn{2}{c}{ Table 1. Summary statistics. } & \multicolumn{2}{c}{} \\
\hline Variable & Mean & Std.dev & Min & Max & Unit \\
\hline $\mathrm{SO}_{2}$ & 0.01594 & 0.010410 & 0.002422 & 0.060656 & Tones per capita \\
soot & 0.00704 & 0.005447 & 0.000416 & 0.0311248 & Tones per capita \\
FDI & 0.02524 & 0.022545 & 0.000673 & 0.1140181 & - \\
$\mathrm{H}$ & 8.77742 & 1.091149 & 6.378 & 13.119 & Year \\
$\mathrm{CH}$ & 0.84788 & 0.087101 & 0.362222 & 0.981284 & $\%$ \\
DH & 0.15211 & 0.087101 & 0.018716 & 0.6377773 & $\%$ \\
industry & 0.47030 & 0.076266 & 0.197596 & 0.615 & \% \\
capital & 2.35680 & 2.230162 & 0.244085 & 13.6143 & 10,000 Yuan per capita \\
unemployment & 0.03606 & 0.007370 & 0.006 & 0.065 & \% \\
energy & 5.75917 & 3.238355 & 1.611788 & 17.5761 & Tonnes of standard coal/Yuan \\
\hline
\end{tabular}


high pollution industries to promote employment. Therefore, the local government will lose its independence because of the high unemployment rate. This paper selects the registered unemployment rate to show the employment situation in various regions.

4) Degree of industrialization

Different industries have different demand of capital and energy and the impacts on the environment is different. The second industry, especially the industrial sector, is an important factor to cause environmental pollution. In this paper, we select the ratio of second industry output value to GDP to measure the impact of regional industrial structure on the quality of the environment.

5) Population density

At the same level of income and pollution, the population density is higher in the region will enlarge the pollution of the marginal damage, which will lead to higher pollution industries against the sound. It is because of this forced mechanism to force enterprises to update the technology to use clean production and encourage local governments to introduce environmentally friendly enterprises.

The data used in this paper come from China Statistical Yearbook, China Environmental Statistics Yearbook and China Statistical Yearbook of labor force. In order to eliminate the impact of price factor, monetary variables are used in 1986 base period. Considering the data available and sample consistency, finally the 19992012 national 29 provinces, municipalities and autonomous regions panel data is used (because of the problem of missing data, excluding Tibet Autonomous Region, Hong Kong, Macao and Taiwan regions, and computed data of Chongqing City in Sichuan Province).

\section{Estimation Result}

In this paper, we use Stata 12 to estimate the Equations (1), (2), (3), and the regression is based on the double fixed effect model.

Table 2 is the estimation result. Firstly, the coefficients and symbols of the main variable FDI and the interaction terms of human capital and FDI are analyzed. Under the condition of total human capital stock $(\mathrm{H})$, the coefficient of FDI is positive, which indicates that the increase of FDI will aggravate the environmental pollution, but to verify whether the "pollution heaven hypothesis" is work, we must also analyze the coefficient of interaction. In order to make the analysis more intuitive, we take the industrial sulfur dioxide as an example, three regression coefficients are substituted into the model (1), (2), (3). And then, we can get the marginal effects of FDI on the environment pollution under the condition of different types of human capital with respect to FDI variable, the results are follow:

$$
\begin{gathered}
\frac{\partial P_{\text {so } 2}}{\partial \mathrm{FDI}}=0.612-0.0675 \mathrm{H} \\
\frac{\partial P_{\text {so } 2}}{\partial \mathrm{FDI}}=-0.533+0.652 \mathrm{CH} \\
\frac{\partial P_{\text {so } 2}}{\partial \mathrm{FDI}}=0.119-0.652 \mathrm{DH}
\end{gathered}
$$

Equation (7) shows that the coefficient of FDI is positive, while the interaction variable (FDI $\times H)$ is negative, and the total human capital $(H)$ decide the total marginal effect of symbols, when total human capital $(H)$ higher than a certain degree, the sign of the total marginal effect is negative, that to say, in the area of higher total human capital, FDI has emission reduction effect, "pollution heaven hypothesis does not hold, and vice versa. Here the conclusion consistent with Lian et al. [18]. We pay more attention on the environmental effects of FDI, which is based on the constraints of heterogeneous human capital and homogeneous component, and the equation (8) and (9) show these results. First look at the equation (8), under the homogeneous human capital constraints $(\mathrm{CH})$, although the FDI coefficient is negative, but the interaction term coefficient (FDI $\times \mathrm{CH})$ is positive, which means that with the increase of the homogeneous human capital, FDI is inclined to aggravate the deterioration of the quality of the environment. And then look at equation (9), which FDI coefficient is positive, the coefficient of the interaction term $(\mathrm{FDI} \times \mathrm{DH})$ is negative, whether marginal effect of FDI the environment pollution is positive depends on the size heterogeneity of human capital, in the area of higher idiosyncratic human capital, FDI has emission reduction effect, and vice versa. In summary, FDI combine with high regional 
Table 2. Results of estimate.

\begin{tabular}{|c|c|c|c|c|c|c|}
\hline & (1) & (2) & (3) & (4) & (5) & (6) \\
\hline Variables & $\mathrm{SO}_{2}$ & Soot & $\mathrm{SO}_{2}$ & Soot & $\mathrm{SO}_{2}$ & Soot \\
\hline \multirow[t]{2}{*}{ FDI } & $0.612^{* * *}$ & $0.221^{*}$ & $-0.533^{* * *}$ & $-0.271^{*}$ & $0.119^{* * *}$ & $0.0539^{*}$ \\
\hline & $(5.12)$ & $(2.13)$ & $(-4.06)$ & $(-2.40)$ & $(4.87)$ & $(2.56)$ \\
\hline \multirow[t]{2}{*}{$H \times$ FDI } & $-0.0675^{* * *}$ & $-0.0243^{*}$ & & & & \\
\hline & $(-4.83)$ & $(-2.00)$ & & & & \\
\hline \multirow[t]{2}{*}{$\mathrm{CH} \times \mathrm{FDI}$} & & & $0.652^{* * *}$ & $0.325^{*}$ & & \\
\hline & & & $(4.40)$ & (2.55) & & \\
\hline \multirow[t]{2}{*}{$\mathrm{DH} \times \mathrm{FDI}$} & & & & & $-0.652^{* * *}$ & $-0.325^{*}$ \\
\hline & & & & & $(-4.40)$ & $(-2.55)$ \\
\hline \multirow[t]{2}{*}{ industry } & $0.0286^{* * *}$ & 0.00349 & $0.0239^{* * *}$ & 0.00130 & $0.0239^{* * *}$ & 0.00130 \\
\hline & $(4.71)$ & $(0.66)$ & (3.89) & $(0.25)$ & (3.89) & $(0.25)$ \\
\hline \multirow[t]{2}{*}{ capital } & $0.000965^{* * *}$ & $0.000557^{*}$ & $0.00107^{* * * *}$ & $0.000654^{* *}$ & $0.00107^{* * *}$ & $0.000654^{* *}$ \\
\hline & (3.88) & (2.58) & $(4.10)$ & (2.93) & $(4.10)$ & (2.93) \\
\hline \multirow[t]{2}{*}{ density } & -0.00000906 & -0.00000155 & $-0.00000749^{* * *}$ & -0.000000902 & $-0.00000749^{* * *}$ & -0.000000902 \\
\hline & $(-5.88)$ & $(-1.16)$ & $(-4.86)$ & $(-0.68)$ & $(-4.86)$ & $(-0.68)$ \\
\hline \multirow[t]{2}{*}{ unemployment } & 0.0108 & 0.0226 & 0.00457 & 0.0181 & 0.00457 & 0.0181 \\
\hline & $(0.22)$ & $(0.52)$ & $(0.09)$ & $(0.42)$ & $(0.09)$ & $(0.42)$ \\
\hline \multirow[t]{2}{*}{ energy } & $0.000999^{* * *}$ & $0.000602^{*}$ & $0.000897^{* *}$ & $0.000586^{*}$ & $0.000897^{* *}$ & $0.000586^{*}$ \\
\hline & (3.54) & $(2.46)$ & (3.19) & (2.43) & (3.19) & (2.43) \\
\hline$N$ & 401 & 401 & 401 & 401 & 401 & 401 \\
\hline r2 & 0.471 & 0.304 & 0.465 & 0.309 & 0.465 & 0.309 \\
\hline r2_a & 0.398 & 0.209 & 0.392 & 0.214 & 0.392 & 0.214 \\
\hline$F$ & 15.65 & 7.677 & 15.30 & 7.855 & 15.30 & 7.855 \\
\hline
\end{tabular}

Note: ${ }^{*}$ Significant at $10 \%$ level; ${ }^{* *}$ significant at $5 \%$ level; ${ }^{* * *}$ significant at $1 \%$ level. The value in bracket is T-statistics.

human capital has emission reduction effect, but in human capital, really caused by FDI's positive environmental effects is idiosyncratic human capital, and improve the coessential human capital will result in FDI has effect of the environmental deterioration.

For the analysis of control variables, results show that the density of material capital raises to exacerbate the deterioration of the environment, suggests that the material capital density increase mainly from the increase of high energy consumption, high pollution of industrial equipment, do not produce the emission reduction effect of technological progress. In the aspect of industrial structure, although increase in the proportion of the second industry will improve both industrial pollutant emissions, but only industrial sulfur dioxide results is at the $5 \%$ level significance, which may due to the sulfur dioxide is main emission in the process of industrial production. Industrial production cannot be avoided energy use, the use of fossil energy is an important reason leading to pollutant generation and deterioration of the environment, so consistent with expectation, the increase in energy consumption have exacerbated the emissions of two pollutants. The empirical results of unemployment rate and population density are in line with expectations, but the results are not significant, so they cannot determine their impact on industrial pollution emissions.

\section{Conclusions}

This paper is the first study of FDI impact on environmental pollution from the perspective of heterogeneous human capital. It has used provincial socioeconomic and environmental data and has investigated how human 
capital and its different components influence the relationship between FDI and pollution emissions in China. Our results have show that the impact of FDI on pollution emissions is highly dependent on the level of human. But each part of human capital has different effects on the environmental effects of FDI. In the total human capital, the key of FDI emission reduction effect is the heterogeneous human capital. Coessential human capital formed by the middle and lower education of the total human capital is not conducive to the spread of emission reduction technology, which leads to the deterioration of the environment of FDI. The findings suggest "pollution heaven hypothesis” holds only in provinces.

For provinces with a high level of heterogeneous human capital, FDI is negatively related to pollution emissions. In contrast, for provinces with a low level of heterogeneous human capital, FDI is positively related to pollution emissions.

The findings in this study have important policy implication. The fast economics growth has turn off China into one of the largest pollution producers in the world, and FDI is regarded as an engine or catalyst for this growth process. Evidence from this study suggests that “pollution heaven hypothesis” is appropriate only to provinces with a low level of heterogeneous human capital. Therefore, if China needs to maintain fast growth and reduce pollution emissions, the government shall be encouraged to develop high education to raise the national level of heterogeneous human capital rather than the stringency of environmental regulation or standard.

\section{References}

[1] Sha, B. and Shi, T. (2006) The Environmental Effect of FDI: An Analysis based on Provincial Panel Dataset in China. World Economy Study, No. 25, 18-25.

[2] Fu, J.Y. and Li, L.S. (2010) FDI, Environmental Regulation and Pollution Haven Effect: Empirical Analysis of China's Provinces Panel Data. Journal of Public Management, No. 7, 65-74.

[3] Zhang, Y. and Jiang, D.C. (2014) FDI, Government Regulation and the Water-Pollution in China: An Empirical Test Based on the Decomposition of Industry Structure and the Technology Progress. China Economic Quarterly, 13, 491514.

[4] He, J. (2006) Pollution Haven Hypothesis and Environmental Impacts of Foreign Direct Investment: The Case of Industrial Emission of Sulfur Dioxide $\left(\mathrm{SO}_{2}\right)$ in Chinese Provinces. Ecological Economics, 60, 228-245. http://dx.doi.org/10.1016/j.ecolecon.2005.12.008

[5] Xu, H.L. and Deng, Y.P. (2012) Does Foreign Direct Investment Lead to Environmental Pollution in China? A Spatial Econometric Study Based on Chinese Provincial Panel Data. Management World, No. 2, 31-43.

[6] Nie, F. and Liu, H.Y. (2015) Correlation Analysis of FDI, Environmental Pollution and Economic Growth: An Empirical Examination Based on Dynamic Simultaneous Equation Model. Journal of International Trade, No. 2, 72-83.

[7] List, J.S. and Co, C.Y. (2000) The Effects of Environmental Regulations on Foreign Direct Investment. Journal of Environmental Economics and Management, 40, 1-20. http://dx.doi.org/10.1006/jeem.1999.1095

[8] Xing, Y.Q. and Kolstad, C.D. (2012) Do Lax Environmental Regulations Attract Foreign Investment? Environmental and Resource Economics, 21, 1-22. http://dx.doi.org/10.1023/A:1014537013353

[9] Zhang, J. and Fu, X.L. (2008) FDI and Environmental Regulation in China. Journal of the Asia Pacific Economy, 13, 332-353. http://dx.doi.org/10.1080/13547860802131326

[10] Baek, J. and Koo, W.W. (2009) A Dynamic Approach to the FDI-Environment Nexus: The Case of China and India. Journal of International Economics, 13, 87-108. http://dx.doi.org/10.11644/kiep.jeai.2009.13.2.202

[11] Cole, M.A., Elliott, R.J.R. and Zhang, J. (2011) Growth, Foreign Direct Investment and the Environment: Evidence from Chinese Cities. Journal of Regional Science, 51, 121-138. http://dx.doi.org/10.1111/j.1467-9787.2010.00674.x

[12] Birdsall, N. and Wheeler, D. (1993) Trade Policy and Industrial Pollution in Latin America: Where Are the Pollution Havens. The Journal of Environmental Development, 2, 137-149. http://dx.doi.org/10.1177/107049659300200107

[13] Eskeland, G.S. and Harrison, A.E. (2003) Moving to Greener Pastures? Multinationals and the Pollution Haven Hypothesis. Journal of Development Economics, 70, 1-23. http://dx.doi.org/10.1016/S0304-3878(02)00084-6

[14] Huq, M. and Wheeler, D. (1993) Pollution Reduction without Formal Regulation: Evidence from Bangladesh. Environment Department Working Paper, 1993-39, World Bank, Washington DC.

[15] Pargal, S. and Wheeler, D. (1996) Informal Regulation of Industrial Pollution in Developing Countries: Evidence from Indonesia. Journal of Political Economics, 104, 1314-1327. http://dx.doi.org/10.1086/262061

[16] Hartman, R.S., Huq, M. and Wheelrt, D. (1997) Why Paper Mills Clean Up: Determinants of Pollution Abatement in four Asian Countries. Policy Research Department Working Paper, No. 1710, World Bank, Washington DC. 
[17] Afsah, S., Laplante, B. and Wheelrt, D. (1996) Controlling Industrial Pollution: A New Paradigm. Working Paper, No. 1672, Policy Research Department, World Bank, Washington DC.

[18] Copeland, B.R. and Taylor, M.S. (2004) Trade, Growth, and the Environment. Journal of Economics Literature, 42, 7-71. http://dx.doi.org/10.1257/.42.1.7

[19] Dean, J.M., Lovely, M.E. and Wheeler, D. (2009) Are Foreign Investors Attracted to Weak Environmental Regulations? Evaluating the Evidence from China. Journal of Development Economics, 90, 1-13. http://dx.doi.org/10.1016/j.jdeveco.2008.11.007

[20] Caselli, F. and Coleman, W.J. (2001) Cross-Country Technology Diffusion: the Case of Computers. The American Economic Review, 91, 328-335. http://dx.doi.org/10.1257/aer.91.2.328

[21] Romer, P.M. (1991) Endogenous Technological Change. Journal of Political Economics, 98, 71-102. http://dx.doi.org/10.1086/261725

[22] Lan, J., Kakinaka, M. and Huang, X.G. (2011) Foreign Direct Investment, Human Capital and Environmental Pollution in China. Environment Resource Economics, 51, 255-275.

[23] Li, Z.H. and Liu, H.H. (2012) Are there Threshold Effects of FDI on Environment?: Evidence from 220 Cities in China. Finance \& Trade Economics, No. 8, 101-108.

[24] Yan, J. and Lu, J.Y. (2014) The Threshold Effect of Foreign Direct Investment on Environmental Pollution: An Analysis Based on the Panel Data Derived from 247 Cities of China. World Economy Studies, No. 8, 81-86.

[25] Ding, D.H. and Liu, Z.B. (1999) From Human Capital to Heterogeneous Human Capital. Productivity Research, No. 3, 3-9.

[26] Yang, H.Y. (2008) On Idiosyncratic Human Capital. The Ideological Front, No. 2, 37-41.

[27] Luo, Y., Wang, Y. and Fan, Z.J. (2013) Heterogeneous Human Capital, Regional Specialization and Income Disparity: From the Perspective of New Economic Geography. China Industrial Economics, No. 2, 31-43.

[28] Liu, Z.Y., Hu, Y.Y. and Yi, X.R. (2008) Testing for the Mechanism of Impacts of Heterogeneous Human Capital on Economic Growth. The Journal of Quantitative \& Technical Economics, No. 4, 86-96. 